\title{
New development of a remotely operated falling wedge
}

\author{
by C. Kevin Lyons ${ }^{1}$
}

\begin{abstract}
A series of projects has developed an alternate cutting pattern that prevents a tree from moving while the faller is cutting at the base and a tool to initiate falling once the faller is in the clear. This specific project developed a second prototype of a remotely operated wedge for use when manually falling trees. The second prototype reduced the friction in the drive train and increased the mechanical advantage, and this increased the separation force produced for a given input torque by a multiple of approximately four, depending on the magnitude of the input torque. In this project, success means the tree did not begin to displace until the remotely operated wedge was inserted and activated. When using the second prototype and permitting the faller to vary the cutting pattern depending on tree imbalance, the success rate was increased from $91 \%$ when using the first prototype to $98 \%$. Further testing is required in larger timber and with other fallers to determine if the high success rate can be maintained in these conditions.
\end{abstract}

Keywords: safety, mechanical design, tree felling

\section{RÉSUMÉ}

Une série de projets a permis de mettre au point une méthode alternative de coupe qui évite que larbre ne bouge lorsque l'abatteur fait une entaille à la base et un outil pour amorcer la chute de larbre lorsque l'abatteur sést éloigné. Ce projet-ci a porté sur la mise au point d'un second prototype de coin actionné à distance pour labattage manuel des arbres. Le second prototype minimisait la friction dans le mécanisme d’entraînement et en augmentait la force mécanique ce qui accroissait denviron quatre fois la force de séparation pour un même torque à lentrée, selon le niveau de torque appliqué. Le succès de ce projet se mesure par le fait que larbre ne commençait pas à se déplacer tant que le coin actionné à distance nétait pas mis en marche. Avec le second prototype et en autorisant l'abatteur à modifier le patron de coupe, il a été possible de hausser le taux de succès à $98 \%$ par rapport au premier prototype (91\%). Il faudra poursuivre les essais sur des arbres de plus forte dimension et avec d'autres abatteurs pour vérifier si le taux de succès se maintient dans de telles conditions.

Mots-clés : sécurité, concept mécanique, abattage d’arbres

C. Kevin Lyons

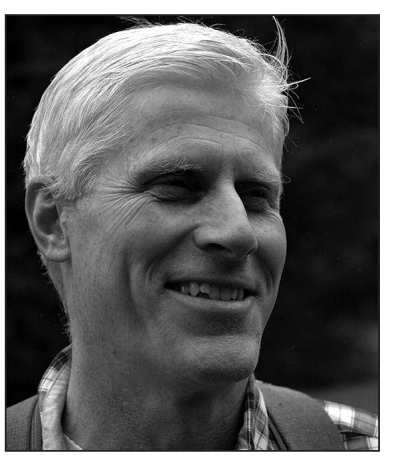

\section{Introduction}

The fatality summaries in the annual WorkSafeBC statistic report indicate that fallers continue to be struck and injured by the trees and logs they are working on, and by trees and logs coming from the surrounding forest (WorkSafeBC, 2012). McLeod and Sarkany (2013) note the frequency of fatalities while manually falling trees does not appear to have changed since the estab-

lishment of mandatory certification for professional fallers in British Columbia in 2006. How do we remove the faller from the hazardous zone when a tree or log is beginning to move? Existing methods such as blasting and machine assist are available, but they require a significant interruption to the work process and do not allow for an incremental selection of falling methods based on the severity of the hazards present. What is particularly troubling from a safety perspective is the uncertainty between what is most likely safe (use traditional manual falling methods), and what is definitely not safe (use blasting or machine assist). Currently, there is no intermediate falling method for the faller to select.

Lyons and Noll (2011) suggested using a new system of falling cuts that prevent a tree from moving while the faller is at the base and that permit falling to be initiated by a remotely operated hydraulic flange spreader. The hydraulic flange spreader was found to be limited by the separation force it could produce and the hydraulic hoses were awkward to manage in the forest. Lyons and Ewart (2012) developed a scissor jack that could be driven by an electric drill (the first prototype) to initiate falling when using the new system of falling cuts. The first prototype produced $15.7 \mathrm{kN}$ (kilonewtons) of separation force given an input torque of $30 \mathrm{Nm}$ (newtonmetres). When testing the first prototype under lab conditions, it was found that the aluminum-bronze thrust washer used in the lower trunnion (the protrusion used as a mounting or pivoting point) had a friction coefficient of approximately 0.12 and this resulted in a loss of about half the applied torque. When using the first prototype with the cutting pattern developed by Lyons and Noll (2011) the success rate was increased to $91 \%$; the previous study had a success rate of $78 \%$ when using the hydraulic flange spreader.

This paper presents the development of a second prototype scissor jack for use when manually felling trees, and

${ }^{1}$ Department of Forest Resources Management, University of British Columbia, Vancouver, B.C., Canada V6T 1Z4. Email: kevlyons@mail.ubc.ca 
reports the results from a small field trial conducted to determine if the design changes increased the success rate. The objectives for the second prototype were to increase the separation force produced for a given input torque and to operate the jack with a wireless remote control.

\section{Second Prototype Design}

The second prototype (Fig. 1) still uses a Nook Industries 750-0200-SBN7202 ball-screw; however, two $7202 \mathrm{~B}$ angular contact ball bearings are housed in the lower trunnion and oriented to take the thrust of the ball screw. The objective is to reduce friction in the driveline. In the second prototype, the arms connecting the trunnions to the jaws (Fig. 1, point C) were elongated to $123 \mathrm{~mm}$ in order to increase the mechanical advantage. The dimensions of the jaw (Fig. 1 points A to C) were kept the same as in the first prototype. The changes in the arm length produced a ratio of the horizontal distance between points $\mathrm{C}$ and $\mathrm{E}$ to the horizontal distance between points $\mathrm{C}$ and $\mathrm{A}$ of $115 \mathrm{~mm} / 40 \mathrm{~mm}=2.88$ (when the jaws are closed). The other change made in the second prototype was to adapt a wireless remote control to a Milwaukee 0721-20 angle driver. Due to the small budget for this project, the remote control unit was housed in an external box attached to the driver. It was found in the field that remote control of the second prototype was not limited by distance; it was common for the operator to be located $30 \mathrm{~m}$ from the tree being felled. The remote control was reliable, it was not affected by light rain or the impact of falling off the tree once the tree had begun to fall on its own. In the future, a more elegant and lighter remote control can be designed to fit within the drive motor unit.

If friction in the driveline is ignored then an equation to estimate the theoretical separation force can be developed as a function of the input torque. The theoretical separation force will be compared to the measured separation force from lab tests. In lab tests, the distance between the jaws was set at $53 \mathrm{~mm}$ and in this position, the ratio of the distance between points $\mathrm{C}$ and $\mathrm{E}$ to the horizontal distance between points $\mathrm{C}$ and $A$ is 2.79. The Nook Industries 750-0200-SBN7202 ball screw requires $8.89 \mathrm{E}-4 \mathrm{Nm}$ of torque to lift a $1 \mathrm{~N}$ load. Thus:

(1) $F_{\text {theoretical }}=\left(\frac{2.79}{1000}\right)\left(\frac{1}{8.89 E-4}\right) T_{\text {in }}=3.14 T_{\text {in }}$

Here $F_{\text {theoretical }}$ is the separation force in $\mathrm{kN}$ when ignoring driveline losses, and $T_{\text {in }}$ is the input torque applied to the ball screw in $\mathrm{Nm}$.

\section{Second prototype results Separation force}

The jaws of the second prototype are designed to provide two stages of contact with the notch in the tree. In the first stage, the contact point is closer to the pin and there is a higher mechanical multiplication for breaking the uncut strap and initiating falling; in the second stage, the contact point shifts farther away from the pin and permits a longer travel to keep pushing the tree until gravity can continue the motion. The exact contact point at a particular jaw position is difficult to

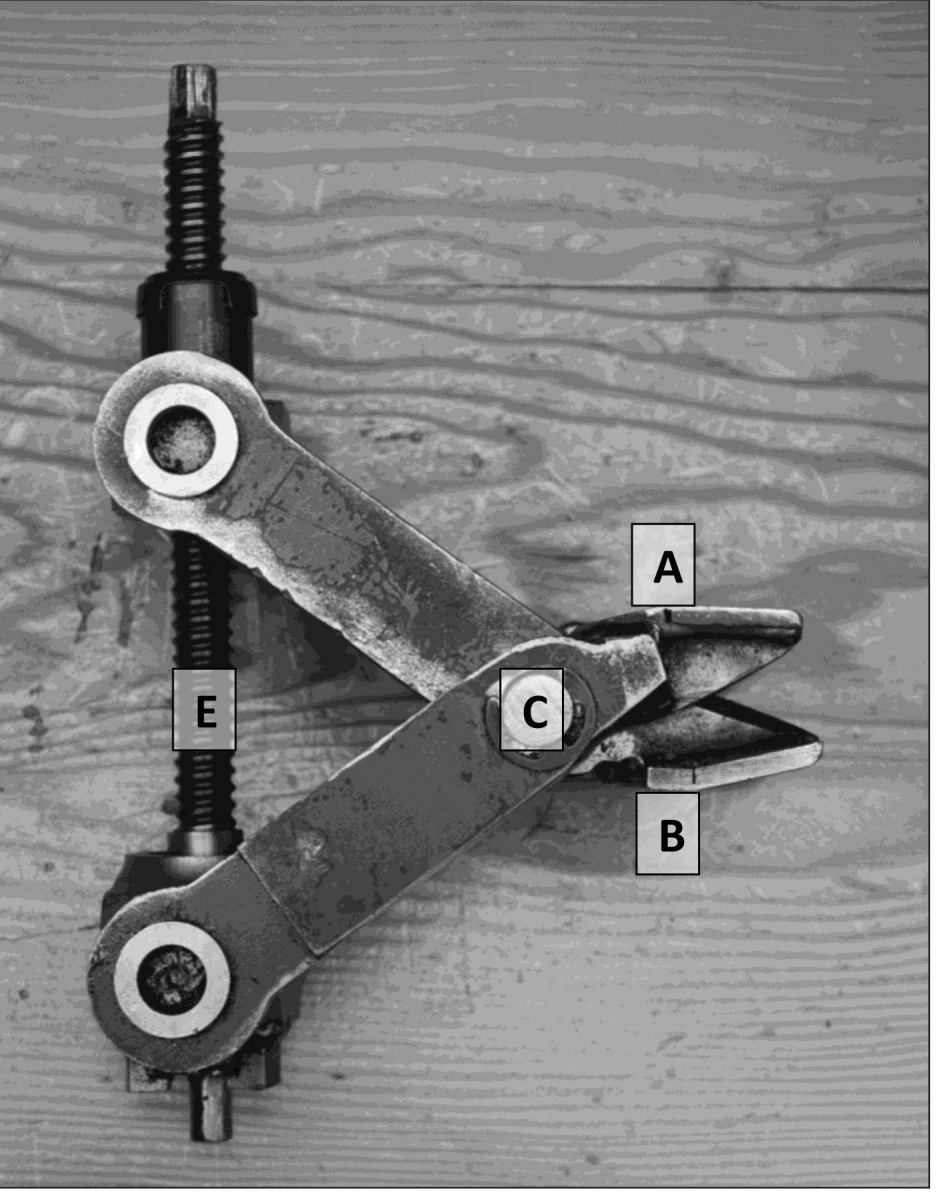

Fig. 1 Second prototype

estimate because the wood will deform to accommodate local stress concentrations and, in fact, it is an area of contact with a non-uniform stress field rather than a point. Lindroos et al (2007) realized a similar problem when studying felling levers. To more accurately measure the separation force for a given input torque, the second prototype was mounted between two rigid plates on a Material Testing System MTS 810. The jaws were opened so the distance between A and B was $53 \mathrm{~mm}$, which resulted in the contact points being $39 \mathrm{~mm}$ from the pin, and the ball screw (E) being $109 \mathrm{~mm}$ from the pin. In this position the forces applied to the load cell and the support table were normal to A and B. A torque wrench was used to drive the second prototype and for a given run, the torque was initially set at $27.1 \mathrm{Nm}$ and increased by increments of $13.5 \mathrm{Nm}$ up to $47.4 \mathrm{Nm}$. The test was replicated seven times. The maximum input torque for these tests was kept below the estimated maximum operational load to ensure that the second prototype was not damaged and that field tests could be conducted using the same prototype.

The relationship between the jaw separation force and the input torque was linear (Fig. 2), and using the jaw separation force $\left(F_{s}\right)$ as the response variable and the input torque $\left(T_{i n}\right)$ as the explanatory variable, simple linear regression gives:

(2) $F_{s}=1.97 T_{\text {in }}+14.2 \quad\left(\mathrm{~F}_{\mathrm{STAT}}=1624, \mathrm{p}\right.$-value $\left.<0.0000\right)$

Here $T_{\text {in }}$ is in $N m$, and $F_{s}$ is the measured separation force in $\mathrm{kN}$. 


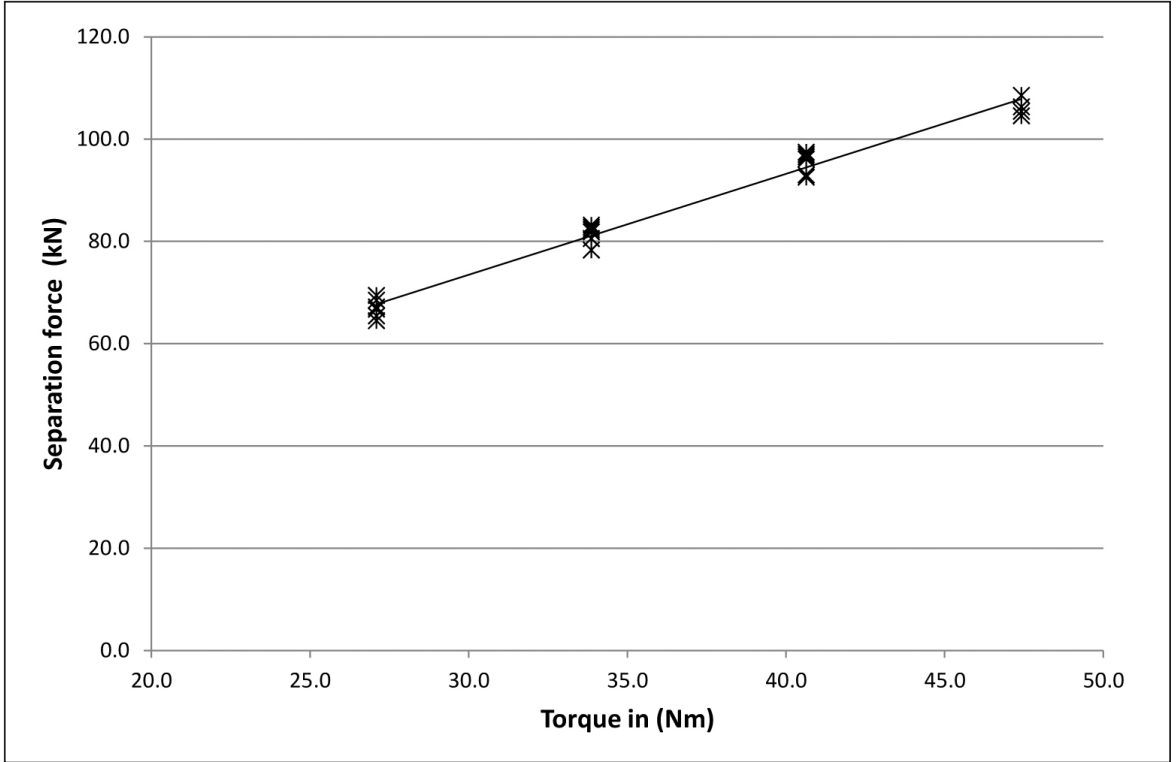

Fig. 2 Lab testing results

When comparing the theoretical separation force estimated by (1) to the measured separation force estimated by (2), while setting $T_{\text {in }}$ to $30 \mathrm{Nm}$ and $60 \mathrm{Nm}$, the measured separation force ranges from $78 \%$ to $70 \%$ of the theoretical separation force. These results indicate the second prototype is losing less than $30 \%$ of the separation force to driveline friction as opposed to the first prototype which lost $50 \%$; this is a significant improvement over the first prototype. For the first prototype $F_{s}$ can be estimated by equation (4) from Lyons and Ewart (2012). Comparing $F_{s}$ produced by the first prototype to the second, it can be seen that the $F_{s}$ produced by the second prototype is 4.7 times greater when $T_{\text {in }}=30 \mathrm{Nm}$ and 3.4 times greater when $T_{\text {in }}=60 \mathrm{Nm}$.

\section{Field testing}

Previous work by Lyons and Noll (2011) developed a new cutting pattern that used an uncut strip of wood (strap) on the backcut side of the tree to prevent the tree from moving while the faller was cutting. The strap could then be broken by a remotely operated tool to initiate falling. Continued experience has produced a more reliable version of this cutting pattern (Fig. 3). The target depth for the undercut is one-quarter to one-third of the stump diameter, and the target thickness of the holding wood is $5 \mathrm{~cm}$. After forming the undercut, the backcut is bored, with the saw being brought forward first to form the holding wood, and then pushed back to form the strap. Once the strap has been formed, the weakening cut is placed at the bottom of the strap and a notch is placed in the weakening cut to fit the tool. The strength of the strap is most strongly controlled by the distance between the backcut and the weakening cut. Refer to Lyons (2013) for a YouTube video demonstrating the use of the second prototype developed in this study.

Two sets of field tests were conducted using the second prototype: a preliminary set where the input torque was applied with a torque wrench, and an operational set where the Milwaukee 0721-20 angle driver was used. The test trees were felled as part of a clear-cut logging operation while the researcher was on site. Eighty-five trees were felled in the preliminary set; 52 in the first group and 33 in the second. The stand consisted of second-growth Tsuga heterophylla (Raf.) Sarg. (western hemlock), Thuja plicata Donn. ex D. Don. (western redcedar), and Pseudotsuga menziesii (Mirb.) Franco (Douglas-fir). Minimum and maximum total tree heights and diameters at stump height were respectively $20 \mathrm{~m}$ to $48 \mathrm{~m}$, and $29 \mathrm{~cm}$ to $110 \mathrm{~cm}$. In this project, success meant the tree did not begin to displace until the remotely operated wedge was inserted and activated. Of the 52 trees in the first group, 45 were successfully felled with the second prototype and seven were failures, overall an $87 \%$ success rate. When evaluating the failures, two trees began to fall before the second prototype was inserted and for the remaining five trees, the second prototype was not able to initiate falling. This result was similar to

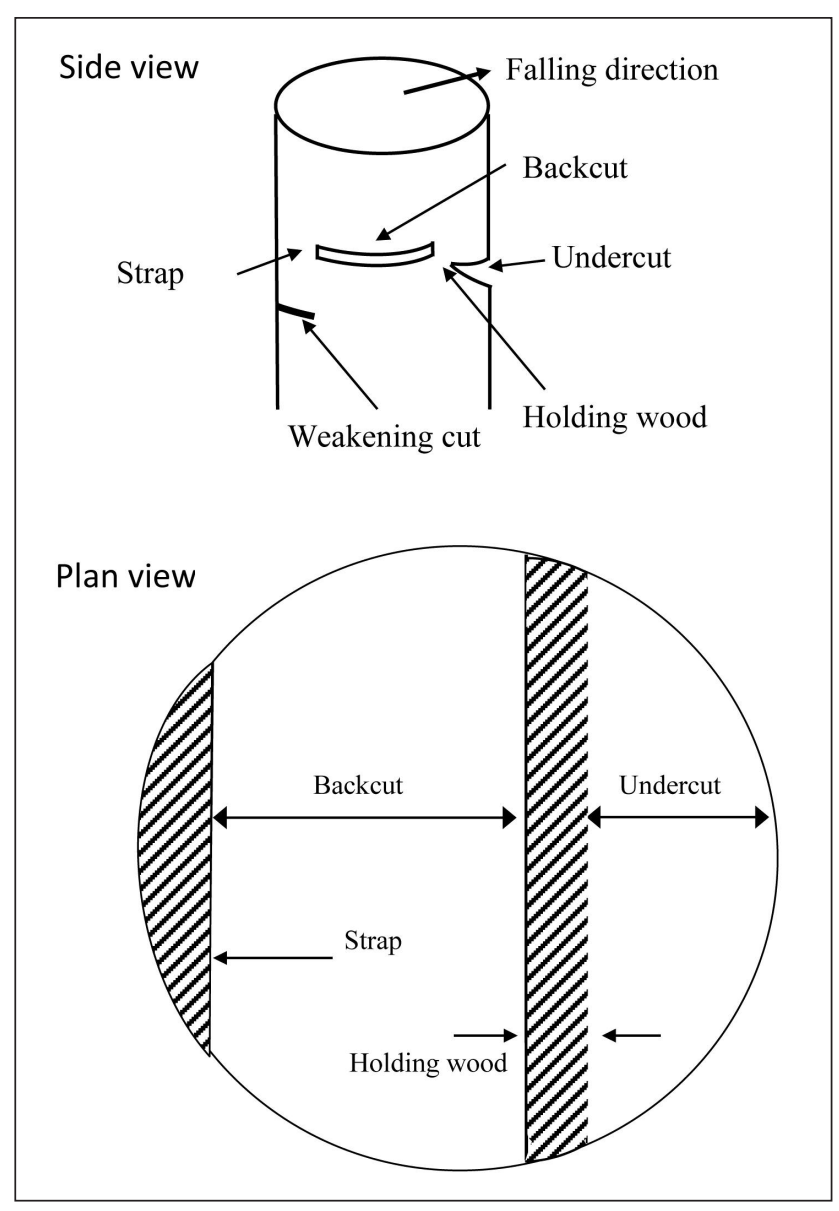

Fig. 3 Cutting pattern with strap 
some of the poorer results with the first prototype; however, on closer inspection it could be seen that 40 trees (77\%) were successfully felled using less than $54.2 \mathrm{Nm}$ of input torque, and of the failures where the second prototype was not able to initiate falling, four trees had a significant imbalance opposite to the direction of fall. Thus, for the second group of trees tested in the preliminary set of tests, the strap was eliminated for trees with a significant imbalance opposite to the direction of fall. In the second group, 33 trees were felled with 31 successes and two failures, producing a $94 \%$ success rate. One of the failures was thought to have an imbalance opposite to the direction of fall and so a strap was not used; however, the imbalance was actually in the direction of fall and the tree began to fall before the second prototype was inserted. For the other tree that failed, the notch was too close to the ground and the ball screw bottomed out on a root, resulting in less force being applied. The improvement in the success rate for the second group was an encouraging result. A note of caution: the direction of a minor imbalance is difficult to determine with $100 \%$ accuracy; thus, a small strap should still be used for trees thought to have a minor imbalance opposite to the direction of fall.

In the operational tests, 64 trees were felled using the Milwaukee 0721-20 angle driver to drive the second prototype. The stand consisted of second growth western hemlock, western redcedar, and Douglas-fir. The minimum and maximum total tree heights and diameters at stump height were respectively, $24 \mathrm{~m}$ to $44 \mathrm{~m}$, and $30 \mathrm{~cm}$ to $89 \mathrm{~cm}$. In the operational tests, the faller was given the freedom to decide whether or not to use a strap and to determine the dimensions of the strap. Of the 64 trees felled, 63 were successful and one was a failure (98\% success rate). The failure was in part due to an error in the distance between the weakening cut and the backcut. The failure had a significant imbalance in the direction of fall (as noted by the faller); however, the distance to the weakening cut was not increased to account for this.

In the operational tests, the faller was permitted to vary the distance between the backcut and the weakening cut (distWC) in order to control the strength of the strap; therefore, which variables had a significant effect on this distance is an important question. Variables included tree species (spp.), stump diameter (dai), tree height (ht), holding wood width (hw), undercut depth (depthUC), imbalance direction (imDIR), imbalance magnitude (imMAG), wind direction (windDIR), and wind magnitude (windMAG). Stump diameter was measured in centimetres inside the bark and is the diameter perpendicular to the holding wood. Tree height was estimated in metres while the tree was standing. Holding wood width and undercut depth were measured in centimetres at the center of the stump. Imbalance direction and wind direction are class variables, with $\operatorname{imDIR}(0)$ and windDIR(0) perpendicular to the direction of fall, $\operatorname{imDIR}(1)$ and wind$\operatorname{DIR}(1)$ in the direction of fall, and $\operatorname{imDIR}(2)$ and windDIR(2) in the opposite direction. Imbalance magnitude and wind magnitude are class variables, with $\operatorname{imMAG}(0)$ and windMAG $(0)$ indicating there was no detectable imbalance or wind, imMAG(1) and windMAG(1) indicating there was a noticeable imbalance or wind but it was below a threshold where its direction was certain, and imMAG(2) and windMAG(2) indicating the magnitude of the imbalance or wind was sufficient that its direction was certain.
Table 1, Distance to weakening cut given imbalance

\begin{tabular}{cccccc}
\hline imDIR & imMAG & $\begin{array}{c}\text { Obser- } \\
\text { vations }\end{array}$ & $\begin{array}{c}\text { Max } \\
(\mathbf{c m})\end{array}$ & $\begin{array}{c}\text { Mean } \\
(\mathbf{c m})\end{array}$ & $\begin{array}{c}\text { Min } \\
(\mathbf{c m})\end{array}$ \\
\hline 0 & 2 & 1 & 19.00 & 19.00 & 19.00 \\
1 & 1 & 45 & 34.00 & 19.64 & 13.00 \\
- & 2 & 2 & 20.00 & 19.00 & 18.00 \\
2 & 1 & 15 & 23.00 & 3.40 & 0.00 \\
- & 2 & 1 & 0.00 & 0.00 & 0.00 \\
\hline
\end{tabular}

The distance between the backcut and the weakening cut is not a continuous variable over its whole range. For trees with an imbalance opposite to the direction of fall, the faller could completely eliminate the strap (i.e., dist $\mathrm{WC}=0$, whereas for trees that required a strap distWC $>12 \mathrm{~cm}$. Table 1 presents the range of dist $W C$ by imbalance direction and magnitude. It can be seen that the faller only classified one tree as having an imbalance perpendicular to the direction of fall, one as having a significant imbalance opposite to the direction of fall, and two having a significant imbalance in the direction of fall. Thus, the faller classified $94 \%$ of the trees felled as having a minor imbalance where there is the expectation that the direction of imbalance could be incorrectly assigned.

In Table 1, it is clear that imbalance direction completely describes when the faller eliminated the strap; however, for trees where the faller did use a strap, it is not clear what variables were significant in explaining the variation in distWC. To consider the variables that affected distWC in the 51 trees where a strap was used, distWC was set as the response variable and the variables recorded during the field tests were set as the explanatory variables in the full model. It can be seen that the full model does not explain a significant amount of the variation in distWC $\left(\mathrm{F}_{\text {STAT }}=1.0155, \mathrm{df}_{1}=11, \mathrm{df}_{2}=39\right.$, $\mathrm{p}$ value $=0.4513)$. The non-significant regression is actually the desired result in this case; it indicates the system of cuts combined with the second prototype provides a method of falling trees that is insensitive to many factors that are considered when manually falling trees.

\section{Discussion}

The high success rate in the operational tests indicates the second prototype, in combination with the novel cutting pattern developed by Lyons and Noll (2011), is sufficiently strong to be a reliable tool for the stand conditions it was tested in; however, these results are stand and faller dependent. Two additional field tests were conducted, both with larger timber and with fallers who had never used the second prototype or novel cutting pattern before. The additional field tests were small, one day with one faller and two days with the other faller, and training consumed the majority of the time.

The observations from these additional field tests are as follows. First, the mechanics of the strap are not always intuitive for a faller. It is not the cross sectional area of the strap (Fig.3) that determines its strength, the important area is the face extending from the inside edge of the weakening cut up to the backcut; the strap fails in shear along this face. Refer to Lyons (2013) for a video describing the mechanics of the strap. Thus, 


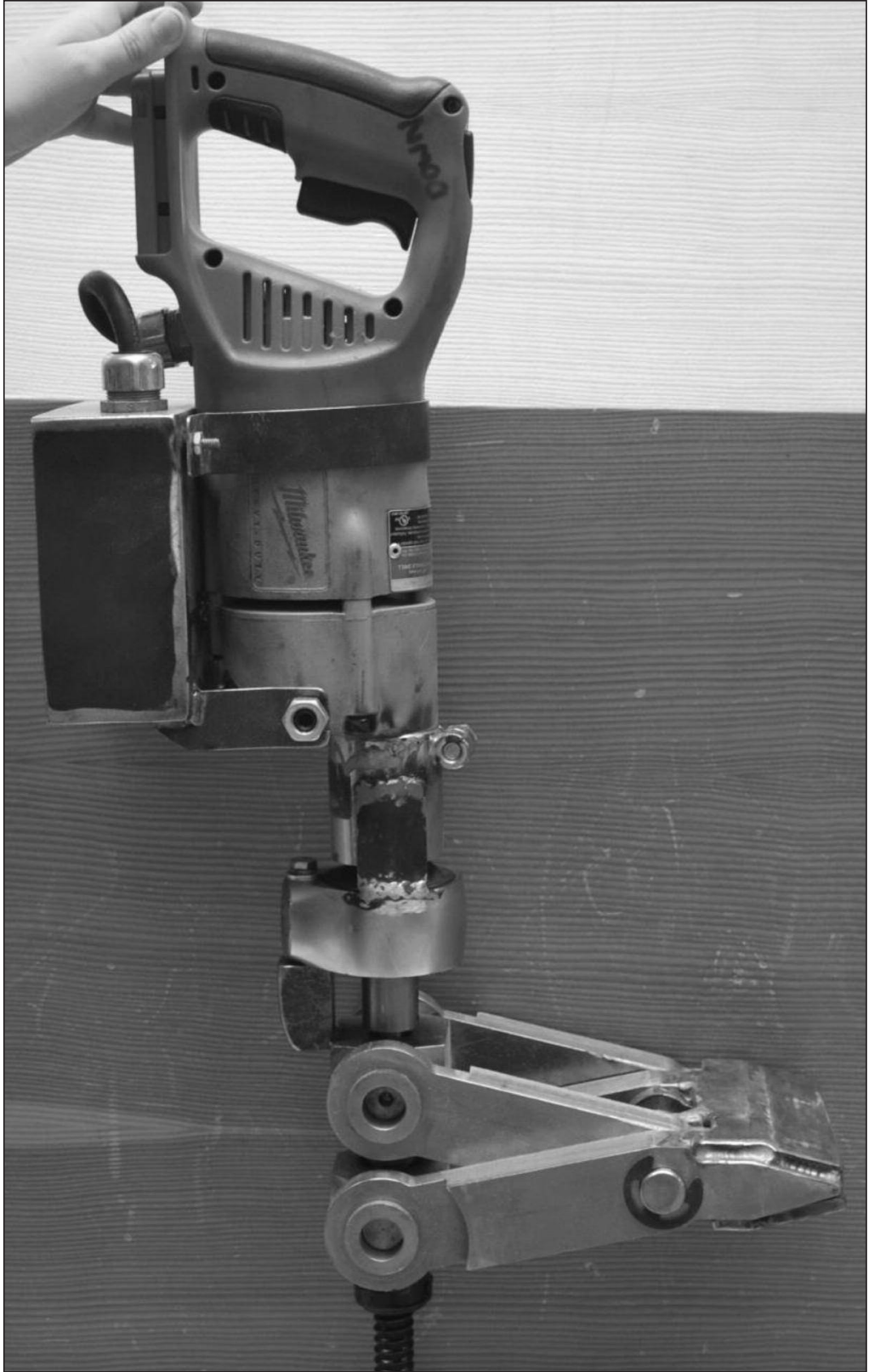

Fig. 4 Third prototype

it is the distance between the backcut and weakening cut that has the greatest effect on the strength of the strap. In addition, it is important to have the weakening cut overlap the backcut so the strap can fail in shear up to the backcut. Second, tree height has a large effect on the moment the second prototype has to overcome or, depending on the direction of imbalance, the moment that the strap has to support. In one of the additional tests, the timber was second-growth and similar in species composition to the operational tests; however, the dominant trees were well over $50 \mathrm{~m}$ tall and it was difficult to balance the dimensions of the strap needed to restrain the trees with the separation force produced by the second prototype. Third, in the other additional set of tests there were some large western redcedar and yellow-cedar (Chamaecyparis nootkatensis (D. Don) Spach.), $120 \mathrm{~cm}$ to $200 \mathrm{~cm}$ dbh. These trees were massive with large, heavy limbs. A torque wrench was used to drive the second prototype when working on these large specimens; however, the surface area of the jaws was not large enough to support this load and the wood tended to crush rather than to break the strap and move the tree. For very large timber, it may be necessary to increase the surface area of the jaws or to use jacking plates.

The total mass of the second prototype and Milwaukee 0721-20 angle driver is $12.9 \mathrm{~kg}(8.2$ $\mathrm{kg}$ and $4.7 \mathrm{~kg}$ respectively), which is over the target mass of $10 \mathrm{~kg}$. The increased weight of the second prototype motivated development of a $3^{\text {rd }}$ prototype. This still uses a Nook Industries 750-0200-SBN7202 ball-screw and two $7202 \mathrm{~B}$ angular contact ball bearings; however, the jaws and arms are constructed of titanium. In addition to using lighter weight material, a 3.3:1 torque multiplier was mounted to the lower trunnion. In this configuration, the 2:1 torque multiplication in the angle drive is lost; however, the 3.3:1 multiplication supplied by the multiplier increases the torque supplied to the ball screw by $65 \%$ compared to the angle drive configuration. The increased torque will increase the maximum separation force but more importantly, it will reduce the load on the motor and permit higher motor speeds for a given separation force. Reducing the load and maintaining higher motor speeds is important for avoiding motor overheating and elevated battery drain. The total mass of the $3^{\text {rd }}$ prototype is $10.4 \mathrm{~kg}(7.2 \mathrm{~kg}$ and $3.2 \mathrm{~kg})$ and this combined with the integrally mounted driver produces a unit that is much more user-friendly (Fig. 4). To-date, the third prototype has not been field-tested.

\section{Conclusions}

This study developed a second prototype remote controlled falling wedge that reduced the frictional losses in the driveline, and increased the separation force for a given input torque. A wireless remote control was installed in a Milwaukee 0721-20 angle driver, which allowed the operator to easily move into the clear before initiating falling. The second prototype was field-tested and it was found that the increased separation force, combined with allowing the faller to vary the dimensions of the strap, increased the success rate from previous versions (up to 98\%). Under operational conditions the most productive day was 40 trees successfully felled with the second prototype.

Testing on a few large western redcedar and yellow-cedar $(>120 \mathrm{~cm} \mathrm{dbh})$ indicated that crushing of the wood under the jaws may become the limiting problem. Two options to overcome this are to either increase the surface area of the jaws or to use jacking plates. Both of these options will increase the weight of the second prototype, but this may be necessary to develop a version that is suitable for falling large old growth trees. 
The second prototype driven by the Milwaukee 0721-20 angle driver worked well in a variety of weather conditions including sun, rain, and snow. When working in secondgrowth timber, a single battery could fell between 20 and 30 trees. Using the angle drive drill worked well as a prototype but resulted in an awkward shape for the tool; therefore, the $3^{\text {rd }}$ prototype mounts the drive motor directly on the tool and this is a much more user-friendly configuration. The remote control was reliable; however, its bulk should be reduced so that it fits within the housing of the drill. A weak point in the second prototype is that the ball bearings in the ball screw run on the screw threads, which are exposed to rain and contaminants. If the second prototype is used in the rain, the ball bearings can rust if they are not lubricated at night. Lubrication is quite simple though; dip the exposed threads in chainsaw bar oil and run the ball screw up and down a few times. A better seal and cover for the ball screw could be a future design feature.

\section{Acknowledgements}

The author gratefully acknowledges the funding support supplied by WorkSafeBC, grant RS2011-IG21, through the Focus on Tomorrow "Innovation at Work" program. The author would also like to acknowledge the valuable contribution made by Guy Chervenka (Evergreen Mechanical Contracting, evermech@telus.net) who has fabricated the many versions of the falling wedge.

\section{References}

Lindroos, O.,T. Gullberg and T. Nordfjell. 2007. Torques from manual tools for direction tree felling. International Journal of Forest Engineering 18(2):40-51

Lyons C.K. 2013. The Wood Duck: a new tree falling tool [online]. Available from http://youtu.be/gBaLwHgSavA [accessed March 31, 2014]

Lyons,C.K. and J. Ewart. 2012. The Wood duck; a new tree falling tool. Western Journal of Applied Forestry. 27(3):137-142

Lyons, C.K. and F.M. Noll. 2011. Optimizing a novel method for manual tree falling. Forestry Chronicle. 87:(04) 537-541

McLeod, C. and D. Sarkany. 2013. Evaluating OHS Interventions: The case study of BC's faller certification program [online]. Available from http://pwhr.sites.olt.ubc.ca/files/2012/04/BC-ForestSafety-Council-Presentation.pdf [accessed March 31, 2014]

WorkSafeBC. 2012. Statistics2011-web- Statistic Report 2011 [online]. Available from http://www.worksafebc.com/publications/ reports/statistics_reports/assets/flipbook/2011/index.html [accessed October 12, 2012]. 